\title{
Effect of Mind-Mapping as a Self-Regulated Learning Strategy on Students' Achievement in Basic Science and Technology
}

\author{
S O Adodo Ph.D. \\ Science and Technical Education Department, \\ Adekunle Ajasin University, Akungba Akoko. P.M B 001, Ondo State, Nigeria. \\ E-mail: so_adodo@yahoo.com, Tel..+2348035064033
}

\section{Doi:10.5901/mjss.2013.v4n6p163}

\begin{abstract}
The study investigates the effect of mind-mapping strategy as a self-regulated learning strategy on students' on achievement in Basic Science and Technology(BST). The design adopted in the research was a quasi-experimental pre-test and post-test method. The population of the study included all junior secondary school science students in Akoko south-west Local Government Area of Ondo State. One hundred and twenty( 120) Basic science students were selected using simple random sampling technique, and were divided into two groups of sixty (60) students out of which thirty(30) male thirty (30) female students were selected per group using stratified random sampling technique. The research hypothesis raised was analyzed using ANCOVA and multiple classification analysis statistics. In conclusion, the study showed that mind-mapping strategy as a $S R L$, helped to improve students performance in BST and should be employed in the classroom as a better approach to teach Basic Science and Technology (BST) as its potency is very clear in this study at improving learners' critical thinking and creative skills. Students should likewise be encouraged to transfer the knowledge and the approach gained to study other Science subject.
\end{abstract}

Keywords: Mind-mapping self regulated learning, student's achievement, instructional strategies, students' gender, Basic science and technology.

\section{Introduction}

Education is accepted worldwide as a measure of international development. The Government is well aware that the technological advancement and social-economic development are dependent on educational development. Hence, the importance of education in the society can be overly emphasized. However, science has contributed immensely to the development of our nation in such areas as communication, computer technology, agricultural researches, commerce and industry and so on. Hence, Basic Science and Technology which is one of the core subjects at the junior level should be given proper attention. Furthermore, without a proper foundation given to the young learners, there would be no main science.

Concept of mind-mapping are spatial representation of concept and their interrelationships that are intended to represent the knowledge structures that humans store in their minds (Jonassen, Beissner, \& Yassi 1993) Concept of mind-mapping is a method that can be used to visualize the structure of knowledge, expressed in the maps is mostly semantic; concept maps are sometimes called semantic networks. Often it is claimed that concept mapping bears a similarity to the structure of long-term memory. Visual symbols are quickly and easily recognized and this can be demonstrated by considering the large amount of logos, maps, arrows, road signs and icons that most of us can recall with little effort. Visual representation also allows the development of holistic understanding that words alone cannot convey, because the graphical form allows representations of parts and whole in a way that is not available in sequential structure of text. (Lawson, 1994)

A number of computer assisted concept on mind-mapping system have been proposed. (Fisher, 1990). Essential for concept mapping tools is their ability to elicit the right of complexity and detail in the students exploration. (Kommers, 1995). In science education, concept mind-mapping has been widely recommended and used in a various ways. It has been used to help teachers and students to build an organized knowledge base in a given discipline (Pankratius, 1990) or a given topic (Kopec, Wood \& Brody, 1990). Furthermore, mind-mapping has been used to assess what the learners know (Wandersee, 1987). The development of science curriculum (Starrs \& Krajcik, 1990) and the evaluation of 
instructional activities for promotion of conceptual understanding (Kinear, Gleeson \& Comerford, 1985) are some other applications of concept mind-mapping. In a mind-mapping as opposed to traditional note-taking or a linear text, information is structured in a way that resembles much more closely how your brain works. It is an activity that is both analytic and artistic. Mind-mapping can be used for note-taking, brainstorming, problem-solving, studying and memorization, planning, researching and consolidating information from multiple source, presenting information, gaining insight on complex subject etc.

\section{Concept maps vs. mind maps}

What's the difference between concept mapping and mind mapping? These two types of visual mapping look very similar, which tends to cause a lot of confusion among people who are just learning about them. Thankfully, the Wikit website contains a very concise and easy to understand comparison of these two concepts.

According to Brett, Chloe, Jennifer, Britta and Chelsea (2012), mind mapping is slightly different from concept mapping in that the mind mapping process starts with a topic at the center of the graphic. Important concepts and phrases are then linked to the center topic on branches which can continue to branch into other concepts and phrases. In addition, the text can be accompanied by images, and color can be used for emphasis or to facilitate organization. Mind maps allow students to create a visual image to enhance their learning and can be used as metacognitive that allows them to make connection into materials in meaningful ways. Farrand, Fearzana and Hennessy (2002) found that mind maps (not only aided medical) students in studying and encourage a deeper level of learning, especially when paired with a problem-based learning curriculum. Mind maps have also been used as reflective tools that allow for broader associations to be made to the materials.

\subsection{The summary of the differences are as follows:}

\subsubsection{Concept maps}

- Are commonly used to organize and represent tacit knowledge.

- Usually contain general concepts at the top of the map, with more specific concepts arrayed hierarchically below.

- Connector lines usually contains keywords or phrases that summarize the relationship between the topics they connect. Such as topic a "causes" topic B.

- Topics may be cross-linked with each other to depict more complex relationships between topics. Topics in mind maps may only have one parent; in a concept map, a topic may have multiple connector lines, each one representing a different relationship.

\subsubsection{Mind maps}

- Tend to be more flexible and personal than concept maps.

- Are used to slice and dice the map's central topic or concept in multiple ways.

- May contain images and color, to make them more visually stimulating

\subsection{Methods Of Mind-Mapping}

The mind-mapping technique which aims at activating both hemisphere of the brain was developed by Tony Buzan toward the end of 1960. Buzan introduced mind-mapping method to the world with his books and developed a system which would pave the way for many people. Basically, what he did was to give up insisting on using the traditional methods for creative minds but instead he aimed at reflecting the functionality of the human brain. These maps allow student to reach the incredible potential of their brain easily. Mind maps allow individual to group the concepts, re-group again and compare the concepts. The movement of the concepts and the synthesizing of it together in new clusters often reveal new ideas. (Findlay \& Lymsden, 1988). The mind-mapping is an organized brainstorming method (Michelo, 1998) mind mapping is a powerful graphic technique which aims at using the brain with full capacity (Buzan \& Buzan 1996). At the same time, studies point out that the use of mind-mapping technique develops thinking skills. The individual does not 
only use words in keeping the constructivist method, pupil constructs the knowledge in their minds when they have real life experience (Isamn, 1999) In the recent years, studies of mind mapping have been conducted with various age group, both positive and negative effects have been encountered. Evrekli et al.(2009) found that according to science teacher candidates, mind mapping can be used in constructive science and technology effectively. To Farrand Hussain, and Hennessy (2002) "Mind maps provide an effective study technique when applied to written material". Taliaferro (1998) determined that students enjoyed the mind-mapping exercise. Goodenough and Woods (2002) performed a qualitative, interpretive case study on two fifth-grade classes and two sixth-grade classes. There were many effects of this study. Students' perceptions of mind mapping were "fun, interesting, and a motivating approach to learning". In addition, students preferred to use mind mapping in an individual situation rather than a group situation because they could express their own ideas for their own meaning.. According to Barth (1984), in order to achieve the lesson objectives, the methods that make students to be active must be used that though constructivist method is based on a principle where the student is active, and where the student gathers his or her prior knowledge and the knowledge gained. The mind-mapping techniques is an alternative technique which can be used in the constructivist approach with respect to its activating prior knowledge and multiple senses by appealing to both hemispheres of the brain.

According to Mona and Adbkhalick (2008) mind mapping is important, effective and useful for students to structure their understanding of environmental concepts in a way which can help the students to be effective. Note takers and which can generate new ideas and associations that they have not thought of before. Graphics organizers assists learning by providing an opportunity for visual, stimuli, brain storming, recording information in none leaner fashion, assessment, checking understanding, problem solving, elaboration, creating analogies, note taking, summarizing, illustrating sequence of events and other creative ways of instruction. Gregory (2002), Trevino (2005) said there are studies showing also mind maps contribute to longer retention of the information through mind maps. Buzan (2005), Akinoglu et al (2007), Keles (2011), helps students to see the connections among the pieces of information. Evrekli et al (2009), Evrekli (2010), enable students to create meaningful links among the pieces of information presented. In Brinkmann (2003)MMP enhanced students' academic achievement and support the formation of conceptual understanding.

\subsection{Uses}

Mind Maps are useful for:

- Brainstorming - individually, and as a group.

- Summarizing information, and note taking.

- Consolidating information from different research sources.

- Thinking through complex problems.

- Presenting information in a format that shows the overall structure of your subject.

- Studying, retaining and recall information.It also promote meaningful learning instead of memorization. (Tony Buzan.(2005) Concept mind maps according to (T-pmar ( 2005) enable teachers to find new ways of discussing concepts with students and identify incorrect learning process. One of the main advantages of concept mind mapping is that they allow for easy recognition of visual symbols. Additionally, they can better explain concepts that words cannot explain, they are students-centered, they encourage teachers-student interaction and they help students retain information longer Conversely, the main disadvantage is that students who are unfamiliar to concept mind mapping may have difficulty in interpreting complicated maps (Kabaca, 2002; 29) further, it may be difficult for younger students to produce their own maps. Nevertheless, other reported benefits of concept mind mapping to teaching and learning in general include, increases in effectiveness of teacher-students communication (Kinchin, 2003, Kinchin \& Alias, 2005). It also includes improved efficiency in note-taking (Stratesson, 2005) and aids in memory and recall (Deschler, 1990).

\subsection{Self-regulated learning}

Self-regulation is an integrated learning process, consisting of the development of a set of constructive behaviors that affect one's learning. These processes are planned and adapted to support the pursuit of personal goals in changing learning environments. From Wikipedia, the free encyclopedia The term self-regulated (process of taking control of and evaluating one's own learning and behavior) can be used to describe learning that is guided by metacognition (thinking 
about one's thinking), strategic action (planning, monitoring, and evaluating personal progress against a standard), and motivation to learn (Butler \& Winne, 1995; Winne 1995; Zimmerman, 1990; Boekaerts \& Corno, 2005).

"Self-regulated learning (SRL) as the three words imply, emphasizes autonomy and control by the individual who monitors, directs, and regulates actions toward goals of information acquisition, expanding expertise, and selfimprovement" (Paris and Paris 2001). In particular, self-regulated learners are cognizant of their academic strengths and weaknesses, and they have a repertoire of strategies they appropriately apply to tackle the day-to-day challenges of academic tasks. Self-regulated learning is a process that assists students in managing their thoughts, behaviors, and emotions in order to successfully navigate their learning experiences. This process occurs when a student's purposeful actions and processes are directed towards the acquisition of information or skills. Generally, models of SRL are separated into phases. One popular cyclical model (see Figure 1) discusses three distinct phases: Forethought and planning phases, performance monitoring phases, and reflections on performance phases (Pintrich \& Zusho, 2002; Zimmerman, 2000). During the forethought and planning phase, students analyze the learning task and set specific goals toward 5 completing that task. When students learn unfamiliar topics, however, they may not know the best ways to approach the task or what goals might be the most appropriate. Teachers and/or more experienced peers often can instruct students on effective approaches in cases like these.

At the performance monitoring phase, students employ strategies to make progress on the learning task and monitor the effectiveness of those strategies as well as their motivation for continuing progress toward the goals of the task. In the final reflection on performance phase, students evaluate their performance on the learning task with respect to the effectiveness of the strategies that they chose. Students are expected to manage their emotions about the outcomes of the learning experience at this stage. These self-reflections then influence students future planning and goals.

According to Sharon,Joseph and Elizabeth (2011), Self-regulated learners' proactive qualities and self-motivating abilities help to distinguish them from their peers. Sharon et al (2011) reported the research work that showed that selfregulated students manipulate their learning environments to meet their needs (Kolovelonis, Goudas, \& Dermitzaki, 2011), they voluntarily offer answers to questions (Elstad \& Turmo, 2010), seek out advice and information (Clarebout et al., 2010), seek out additional resources when needed to master content (Clarebout, Horz, \& Schnotz, 2010) and pursue positive learning climates than their peers who display less self-regulation in the classroom. Other findings from studies also showed that self-regulated learners perform better on academic tests and measures of student performance and achievement (Schunk \& Zimmerman, 2007; Zimmerman, 2008).

In a study of high school students, Labuhn et al. (2010) found that learners who were taught SRL skills through monitoring and imitation were more likely to elicit higher levels of academic self-efficacy (confidence) and perform better on measures of academic achievement compared to students who did not receive SRL instruction. It therefore means that SRL can make the difference between academic success and failure for many students (Graham \& Harris, 2000; Kistner, Rakoczy, \& Otto, 2010). Students who are self-regulated learners believe that opportunities to take on challenging tasks, practice their learning, develop a deep understanding of subject matter, and exert effort will give rise to academic success (Perry et al., 2006). In part, these characteristics may help to explain why self-regulated learners usually exhibit a high sense of self-efficacy (Pintrich \& Schunk, 2002). In the educational psychology literature, researchers have linked these characteristics to success in and beyond school (Corno, et al., 2002; Pintrich, 2000 ) in Sharon(2011)l.

\subsection{Self-Regulated Learning Strategies for Students}

To promote SRL in classrooms, teachers must teach students the self-regulated processes that facilitate learning. These processes often include: goal setting (Winne \& Hadwin, 1998; Wolters, 1998), planning (Zimmerman, 2004); selfmotivation (Corno, 1993; Wolters, 2003; Zimmerman, 2004), attention control (Winne, 1995), flexible use of learning strategies (van de Broek, Lorch, Linderholm, \& Gustafson, 2001), self-monitoring (Butler \& Winne, 1995; Carver \& Scheier, 1990), appropriate help-seeking (Ryan, Pintrich, \& Midgley, 2001), and self-evaluation (Schraw \& Moshman, 1995). This study is now considering MMP as a SRL strategy since SRL allows learners to implement multiple learning strategies across tasks, Self regulated learners are successful because they control their learning environment. They exert this control by directing and regulating their own actions toward their learning goals. Self regulated learning should be used in three different phases of learning. The first phase is during the initial learning, the second phase is when troubleshooting a problem encountered during learning and the third phase is when they are trying to teach others 


\subsection{Sources of Self-Regulated Learning (SRL)}

According to Iran-Nejad and Chissom (1992), there are three sources of self-regulated learning (SRL): Active/executive, dynamic, and interest-creating discovery model. Active/executive self-regulation is regulated by the person and is intentional, deliberate, conscious, voluntary, and strategic. The individual is aware and effortful in using self-regulation strategies. Under this source of SRL, learning happens best in a habitual mode of functioning. Dynamic self-regulation is also known as unintentional learning because it is regulated by internal subsystems other than the "central executive." The learner is not consciously aware they are learning because it occurs "both under and outside the direct influence of deliberate internal control." The third source of self-regulated learning is the interest-creating discovery module, which is described as "biofunctional" as it is developed from both the active and dynamic models of self-regulation. In this model, learning takes place best in a creative mode of functioning and is neither completely person-driven nor unconscious, but it is a combination of both. In Zimmerman et al (1990) SRL was viewed from 4 perspectives.

\subsection{Social Cognitive Perspective}

Self-regulation from the Social Cognitive Perspective looks at the triadic interaction among the person (e.g., beliefs about success), his or her behavior (e.g., engaging in a task), and the environment (e.g., feedback from a teacher). specified three important characteristics of self-regulated learning: monitoring one's activities; self-evaluation of one's performance and reactions to performance outcomes. These help learners accurately to reflects on their progress toward a learning goal, and appropriately adjusts his or her actions to maximize performance, he or she has effectively self-regulated. During a students school career the primary goal of teachers is to produce self-regulated learners by using such theories as Information Processing Model (IPM). By storing the information into long term memory, learner can retrieve it upon demand and apply to tasks, becoming a self-regulated learner. In Jang (2010), self-regulated learning is required for academic performance completed through SDL. In regards to self-regulated learning (SRL) strategies, Jang (2010) reported the studies of, Zimmerman and Martinez-Pons (1988),, Zimmerman, Bandura, and Martinez-Pons (1992) and Zimmerman and Bandura (1994) on integrated learning strategy, based on self-regulated learning which, include, selftesting, organizational transformation, goals and planning, pursuing information, recording and checking, structured environment, strength demonstration and memory. All these opinions are very important in the MMP -learning environment. Jag (2010) also reported that despite the power of self-regulation to motivate learners and to increase their success, few teachers effectively prepare students to learn on their own, encourage students to establish specific goals for their academic work or estimate their competence on new tasks, most teachers don't give students opportunities to self-assess their work and most do not explore student beliefs about themselves as learners. It is upon this background that this study is out to see the effect of MMP as a self regulated learning strategy on student's performance in BST.

\subsection{Application of self-regulated learning in practice}

Edirippulige \& Marasinghe (2011) reviewed evidences of blending of self-regulated learning with new educational programmes such as e-Health teaching using different ICT technologies. There are also many practical applications for self-regulated learning in schools and classrooms today. Paris and Paris (2011) state there are three main areas of direct application in classrooms: literacy instruction, cognitive engagement, and self-assessment In the area of literacy instruction, educators can teach students the skills necessary to lead them to becoming self-regulated learners by using strategies such as reciprocal teaching, open-ended tasks, and project-based learning. Other tasks that promote selfregulated learning are authentic assessments, autonomy-based assignments, and portfolios. These strategies are student-centered and inquiry based, which cause students to gradually become more autonomous, creating an environment of self-regulated learning. However, students do not simply need to know the strategies, but they need to realize the importance of utilizing them in order to experience academic success. According to Dweck and Master, Students who are not self-regulated learners may daydream, rarely complete assignments or forget assignments completely. Those who do practice self-regulation ask questions, take notes, allocate their time effectively, and use resources available to them. In (Laskey \& Hetzel, 2010)., examples of self regulated learning strategies in practice are stated as follows: 


\subsubsection{Self-Assessment:}

fosters planning, assess what skills the learner has and what skills are needed. Allows students to internalize standards of learning so they can regulate their own learning

\subsubsection{Wrapper Activity:}

activity based on pre-existing learning or assessment task. This can be done as a homework assignment. Consist of selfassessment questions to complete before completing homework and then after completion of homework. This will allow the learner to draw their own conclusions about the learning process (Laskey \& Hetzel, 2010).

\subsubsection{Think Aloud:}

This involves the teacher describing their thought process in solving a problem.

\subsubsection{Questioning:}

Following new material, student develop questions about the material..

\subsubsection{Reciprocal Teaching:}

The learner teaches new material to fellow learners (Joseph, 2010).

\subsection{Mind Mapping as a Self Regulatory Instructional Strategy}

Mind Maps were popularized by author and consultant, Tony Buzan.(2005) stated that Mind Maps are more compact than conventional notes, often taking up one side of paper. This helps students to make associations easily, and generate new ideas. If students find out more information after they have drawn a Mind Map, then they can easily integrate it with little disruption. More than this, he said Mind Mapping helps students break large projects or topics down into manageable chunks, so that they can plan effectively without getting overwhelmed and without forgetting something important. A good Mind Map shows the "shape" of the subject, the relative importance of individual points, and the way in which facts relate to one another. This means that they're very quick to review, as students can often refresh information in their mind just by glancing at one. In this way, they can be effective mnemonics - remembering the shape and structure of a Mind Map can give learners the cues they need to remember the information within it. As such, they engage much more of their brain in the process of assimilating and connecting information than conventional notes do

\section{Problem}

Some factors are responsible for the poor performance of students in the compartmentalized science like Chemistry, Physics, Biology and mathematics in recent years. These factors include students' negative attitude to Science which is invariably affecting their interest. On the part of the teachers, the factors include poor method of teaching, incompetency at using ICT and media technology (Adodo 2012), incompetency in handling the new Basic Science and Technology concepts, laziness, and inability to improve on their pedagogy approach in Basic Science and Technology. Hence remain the problem of poor and weak foundation at the basic level.

\section{Purpose Of Study}

Many studies have been conducted to improve students' performance in Sciences at the senior level, only few studies have known or considered mind-mapping as a self-regulated learning strategy for students at the catch them young stage. Thus, this study seeks to research on mind-mapping as a self regulated strategy on students' achievement in some concepts in Basic Science and technology. 


\section{Methodology}

The study is a quasi -experimental research. A total number of 120 Students were used for the study. All the Subjects were drawn from three selected public co-education schools. 60 Students were assigned to each group using simple random sampling technique out of which 30 male and 30 female were selected through stratified random sampling technique. The instrument used in the study was 30 multiple -choice test items developed from the Junior NECO exams BST past questions. The first par of the test instrument seeks information on the bio-data of the responds,

\subsection{Procedure:}

The field assistants who are old teacher $\mathrm{s}$ with little or no idea about mind mapping instructional strategy were trained for two weeks so as to provide them with the training needed to handle the students in the experimental group. They were also provided with the study guide and the instructional materials needed to teach the students the selected topics for the study in BST. How ever the teachers were closely supervised by the researcher. A day to the commencement of the teaching, the pre-test was conducted in all the group to measure their entering behavior and ascertain the homogeneity of the group before the exercise stated. The teaching was done for 4 weeks after which the posttest was administered on the students in all the groups. A retention test was also conducted after 2 week of the whole exercise. The score were collected which served as data measuring the performance the students in all the groups

\subsection{Data Analysis:}

The data were analyzed using ANCOVA and multiple classification analysis, all tested at 0.05 level of significance.

\subsection{Results:}

$\mathrm{HO}_{1}$ There is no significant difference in performance of students exposed to mind mapping self regulatory instructional strategy and those in the conventional group class.

Table1 : Summary of ANCOVA on the achievement and retention Mean Scores of subjects

$\begin{array}{lccccc}\text { Source of variation } & \text { SS } & \text { d.f } & \text { MS } & \text { F } & \text { P } \\ \text { Covariates } & 2188.633 & 4 & 547.158 & 16.008 & 2.45 \\ \text { Pretext scores } & 196.675 & 1 & 196.675 & 6.078 & 3.92 \\ \text { Sex } & 31.294 & 1 & 31.294 & .967 & 3.92 \\ \text { Groups } & 1862.508 & 1 & 1862.508 & 57.554 & 3.92 \\ \text { SEX VS Group } & 15.808 & 1 & 15.808 & .488 & 3.92 \\ \text { Error } & 3721.492 & 115 & 32.361 & & \\ \text { Corrected Total } & 5910.125 & 119 & & & \\ \text { Total } & 4707.000 & 120 & & & \end{array}$

The table above reveals that, $F_{-}$cal 0.488 is less than $F_{-}$tab $(3.92)$ at 0.05 level of significance. This means there is no significant interaction effect of gender and treatment on students' academic achievement in BST. The hypothesis is upheld. It implies that male and female students don't differ in their performance in BST when exposed to mind mapping instructional technique. Similarly the effect of gender on student' performance in BST is not significant at 0.05 alpha level ( $0.697, p>0.05)$ How ever the main effect of treatment on students' performance is significant $(F=57.554, P<$ 0.05) In order to determine the effect of treatment on students' performance in BST, multiple classification analysis (MCA) was used. The results are as shown in the table below. 
Table 2: Multiple Classification Analysis of achievement and retention mean scores of subjects in the different groups

\begin{tabular}{|c|c|c|c|c|c|}
\hline Grand mean $=25.63$ & & & & & \\
\hline Variable+ Category & $\mathrm{N}$ & $\begin{array}{l}\text { Unadjusted } \\
\text { Deviation }\end{array}$ & Eta & $\begin{array}{c}\text { Adjusted for } \\
\text { Independent }+ \\
\text { Covariate deviation }\end{array}$ & Beta \\
\hline Conventional Teaching Method & 60 & -4.03 & & -3.94 & \\
\hline & & & 0.259 & & 0.217 \\
\hline Mapping Method & 60 & 4.02 & & 3.39 & \\
\hline Multiple R2 & & & \multicolumn{2}{|c|}{0.217} & \\
\hline Multiple R & & & \multicolumn{2}{|c|}{0.047} & \\
\hline
\end{tabular}

Eta coefficient is when the contribution of a variable when the effect of the co-variate (pre-test) has not been removed. Beta coefficient is the contribution of a variate (pre-test\} has been removed. Beta weight coefficient also shows the relative effect of each independent variable. Multiple $R^{2}$ is the contribution of the entire independent and intervening variables when considered jointly

The result of the table reveals that with a grand mean 0 25.63. Students' exposed to Mind-mapping strategy had higher adjusted post test mean score of 29.56(25.63+3.93).compared to the Conventional method with an adjusted post test mean score of $21.59(25.63+(-3.94)$. This implied that Mind mapping strategy is more potent a strategy for effective and effecting better performance in BST.

\section{Discussion}

The study shows that the main effect of treatment on students' performance is significant. This is clearly shown from the multiple classification analysis of the achievement and retention as students exposed to mind mapping had high adjustment post test means score compare to their counterparts in conventional groups. This is supported by the Brett (2012) et al. The mind-mapping when used as part of instructional approach is potent at increasing students' achievement score, knowledge and retention. The result of the finding showed that interaction of gender and method does not produce any significant effect on performance of students in BST. This shows that sex may not be a determinant factor in the method of teaching. This is supported by the finding of Alebiosu (1998) that no significant interaction effect on students' gender as far as performance is concerned. Adodo (2004) corroborates this outcome that both sexes when equal encouragement to use their intellectual gifts fully, that both sexes are not differ in their studies. He said further that gender does not affect students' learning of science and their performance He reiterated that less learning difficulties will be encountered by students irrespective of their sexes when the right method and teaching strategies are used. Such method is the MMP as SRL strategy. According to this study, the mind-mapping technique, as confirmed by other study of Ozigul (2012) is also helpful as it aids and helps learners understand and recall information better.

\section{Conclusion and Recommendations}

Base on the findings, it is concluded that with the use of Mind mapping MMP-SRL, strategy students' performance can be improved upon in BST. Also gender does not in any way affect the effectiveness of MMP - SRL in the learning process of BST. MMP-SRL helps students to associate ideas, think creatively, and make connections that one might not otherwise make in the conventional approach. As mind-mapping is a useful technique that helps students learn more effectively, improves the way they record information, supports and enhances their creative problem solving and being valuable at improving students' critical thinking disposition, teachers should adopt it as a method for teaching Basic Science and Technology (BST). More than this, Mind Maps help students remember information, as they hold it in a format that the mind finds easy to recall and quick to review. It also helps the students to improve their innovative and creative thinking.. Students can therefore be encouraged to transfer the knowledge and the approach gained to study other Science subjects To meet up with the technological status of countries like China, Taiwan, Japan, this method is imperative for the teaching and learning of Basic Science and technology in all developing countries across the globe. 


\section{References}

Adodo S.O. (2004), Influence of Gender And Environment on student's performance in Integrated Science in Secondary School Educational Thought. Resaerch. Journal of the Faculty of Education A.A.U, Akungba Akoko 4 (1), 70-77

Andreassen, R. \& Braten, I. (2011). Implementation and effects of explicit reading comprehension instruction in fifth-grade classrooms. Learning and Instruction, 21, 520-537.

Boekaerts, M. \& Corno, L. (2005). Self-regulation in the classroom: A perspective on assessment and intervention. Applied Psychology: An International Review, 54(2), 199-231.

Brinkmann, A. (2003). Graphical knowledge display mind mapping and concept mapping as efficient tools in mathematics education mathematics education Review, 16, 3548.

Bromley, K., Irwin-DeVitis, L., \& Modlo, M. (1995). Graphics organizers: Visual strategies for active learners .New York, NY: Scholastic professional books

Buzan, T. (2005). Mind map handbook. The Ultimate Thinking Test by Tony Buzan Published in march 2005

Evrekli, E., Balım, A.G., \& Inel, D. (2009). Mind mapping applications in special teaching methods courses for science teacher candidates and teacher candidates" opinions concerning the applications. Procedia Social and Behavioral Sciences, 1, 22742279. http://dx.doi.org/10.1016/j.sbspro.2009.01.400

Farrand, P., Hussain, F., \& Hennessy, E. (2002). The efficacy of the 'mind map' study technique. Medical Education, 36, 426431.http://dx.doi.org/10.1046/j.1365-2923.2002.01205.x

Goodenough, K., \& Woods, R. (2002, April). Student and teacher perceptions of mind mapping: A middle school case study. Paper presented at the American Educational Research Association Annual Meeting, New Orleans, LA. Retrieved from http://faculty.ksu.edu.sa/aljarf/Research\%20Library/Mind-mapping/84.pdf

Graham, S., Harris, K. R., \& Mason, L. (2004). Improving the writing performance, knowledge, and self-efficacy of struggling young writers: The effects of self-regulated strategy development. Contemporary Educational Psychology, 30, 207-241.

Gregory,G.H; Chapman,C.(2002).differentiated instructional strategies:one size doesn't fit all. Thousand oaks, CA: Corwins press, inc.

Jong-Ki Lee (2010) The effects of self-regulated learning strategies and system satisfaction regarding learner's performance in elearning environment

Keles, O. (2011). Elementary teacher's views on mind mapping. International conference on New Horizons in education conference proceedings book, 348, 8-9 June, Portugal.

Kinchin (2003) Learning style in Education and TrainingEmerald Group Publishing Ameson.com vol. 48 2/3 2004

Mona, I., \& AdbKhalick, F. (2008). The influence of mind mapping on eighth graders' science achievement. School Science and mathematics, 108(7), 298312

Ornstein and Hack (2001) Memory development on the development of memory. American psychological society.

Paris, S. G., \& Paris, A. H. (2001). Classroom applications of research on self-regulated learning. Educational Psychologist, 36, 89-91.

Pintrich, P. (2000). Multiple goals, multiple pathways: The role of goal orientation in learning and achievement. Journal of Educational Psychology, 92, 544-555.

Pintrich, P. R., \& Zusho, A. (2002).The development of academic self-regulation:

Ryan, A. M., Pintrich, P. R., \& Midgley, C. (2001). Avoding seeking help in the classroom: Who and why? Educational Psychology Review, 13, 93-114.

Schunk, D. H., 2000. Learning Theories In Educational Perspectives. Prentice Hall.

Sharon Zumbrunn, Joseph Tadlock and Elizabeth Danielle Roberts (2011): Encouraging Self-Regulated Learning in the Classroom: A Review of the Literature

Schraw, G., \& Moshman, D. (1995). Metacognitive theories. Educational Psychology Review, 7, 351-371.

Strantesson I. (1998) mind-mapping concepts Oxford advance learners dictionary (7 $7^{\text {th }}$ edition).

Stoeger, H., \& Ziegler, A. (2011). Self-regulatory training through elementary-school students' homework completion. In B. J. Zimmerman, \& D. H. Schunk (Eds.), Handbook of self-regulation of learning and performance (pp. 87-101). New York: Routledge.

Taliaferro, M. (1998). Mindmapping effects on sixth grade students' recall ability. Unpublished master's thesis, Mercer University, Atlanta, Georgia.

Trevino, C. (2005). Mind mapping and outlining: Comparing two types of graphc organizers for learning seventh-grade life science, Texas Tech University: Unpublished PhD Thesis.

Tonks, S. M., \& Taboada, A. (2011). Developing self-regulated readers through instruction for reading engagement. In B. J. Zimmerman, \& D. H. Schunk (Eds.), Handbook of self-regulation of learning and performance (pp. 173-186). New York: Routledge.

Vidal-Arbarca, E., Mana, A., \& Gil, L. (2010). Individual differences for self-regulating task-oriented reading activities. Journal of Educational Psychology, 102(4), 817-826.

Winne, P. H. (1995). Inherent details in self-regulated learning. Educational Psychologist, 30, 173-188.

Winne, P. H. (2009). Self-regulated learning viewed from models of information processing. In B. J. Zimmerman \& D. H. Schunk (Eds.) Self-regulated learning and academic achievement, (2nd ed.) (pp. 153-189). New York: Routledge. 
Winne, P. H., \& Hadwin, A. F. (1998) Studying as self-regulated learning. In D. J. Hacker \& J. Dunlosky (Eds.), Metacognition in educational theory and practice, The educational psychology series. Mahwah, NJ: Erlbaum.

Wolters, C. A. (2003). Regulation of motivation: Evaluating an underemphasized aspect of self-regulated learning. Educational Psychologist, 38, 189-205.

Zimmerman, B. J., \& Martinez-Pons, M. (1990). Student differences in self-regulated learning: Relating grade, sex, and giftedness to self-efficacy and strategy use. Journal of Educational Psychology, 82, 51-59.

Zimmerman, B. J., 1990. Self-regulated learning and academic achievement: An overview. Educational Psychologist, 25(1), pp. 3-17.

Zimmerman, B. J. (2004). Sociocultural influence and students' development of academic self-regulation: A social-cognitive perspective. In D. M. Mclnerney \& S. Van Etten (Eds.), Big theories revisted (pp.139-164). Greenwhich, CT: Information Age. 